\title{
GEOPHYSICAL SIGNATURES OF SUSPECTED AND CONFIRMED IMPACT STRUCTURES, ONTARIO, CANADA
}

\author{
M.H. Armour ${ }^{1,2}$, J. Boyce ${ }^{1}$, D. Zilkey ${ }^{1}$
}

1-School of Geography and Earth Sciences, McMaster University, Hamilton, ON

2-Department of Science and Technology Studies, York University, Toronto ON

Geophysical data are increasingly employed to identify potential impact structures and to model their subsurface structure. In this study we employed 2-D forward magnetic modelling of gravity and magnetic data to investigate the subsurface structure of the Holleford impact crater and two suspected impact structures (Skeleton Lake, Charity Shoal) in Ontario, Canada (Fig. 1). An objective was to determine whether Holleford crater could be used as an geophysical/structural analog for Charity Shoal and Skeleton Lake.

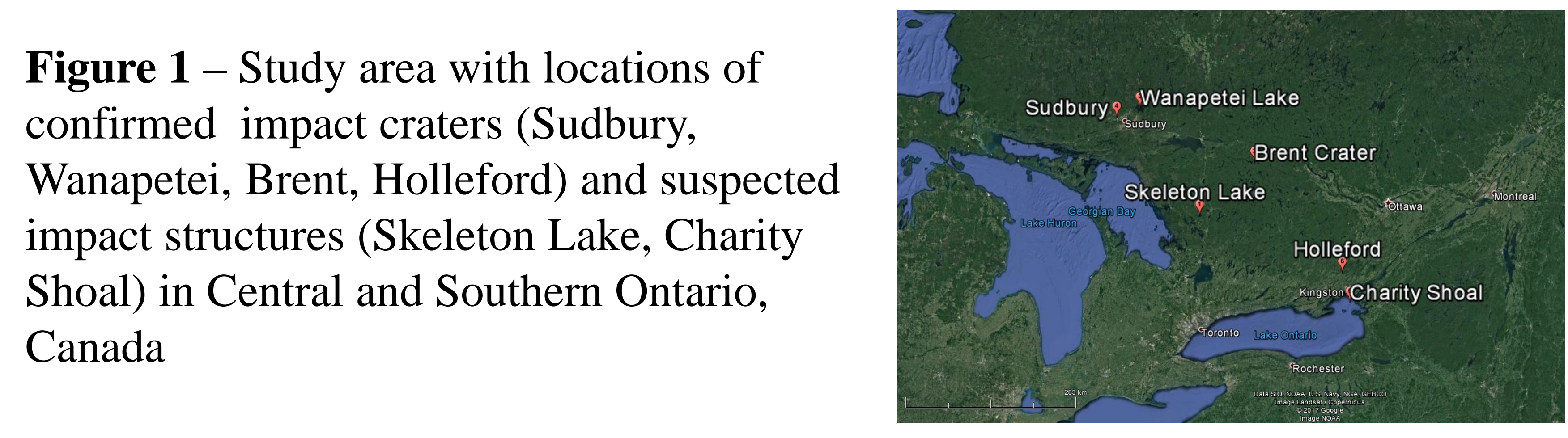

Holleford Crater was identified in 1960 as a simple, $2.4 \mathrm{~km}$ diameter impact crater in Late Proterozoic target rocks (Beals, 1960). The impact origin was confirmed through deep drilling and recovery of breccias with PDF's and highpressure polymorphs. Gravity surveys conducted in the 1950's demonstrate a welldefined $\sim 3 \mathrm{mGal}$ Bouguer anomaly (Fig. 2A) but no magnetic anomaly was identified in aeromagnetic data. Newly acquired ground-based total field magnetic intensity (TMI) surveys conducted in 2016, identified a small $(<20 \mathrm{nT})$ anomaly over the crater basin (Fig. 2C). The lack of a well-defined TMI anomaly is attributed to the low mantic suscep to $\mathrm{D}$ mow met rocks. with a depth of $\sim 500 \mathrm{~m}$.
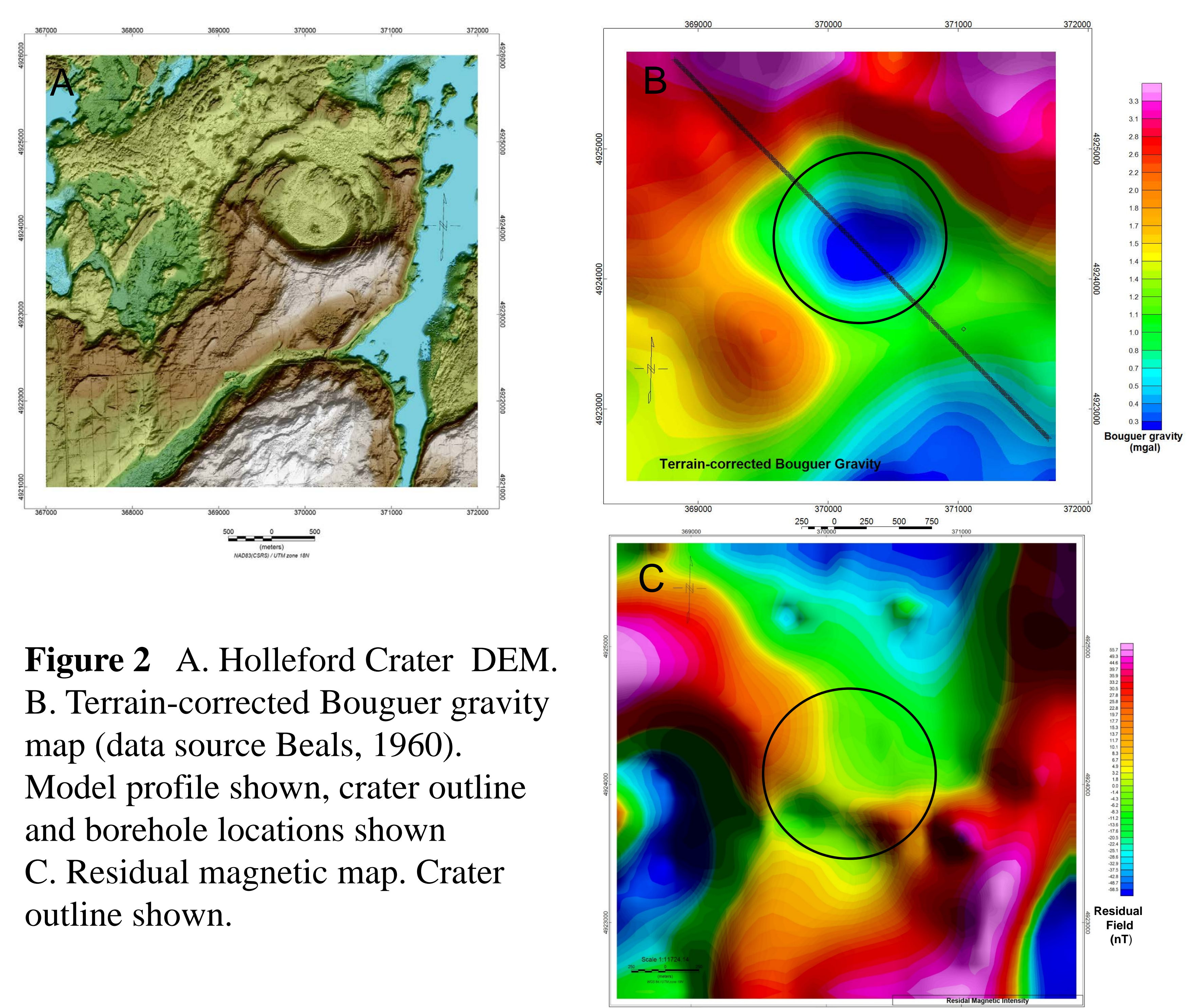

Figure 2 A. Holleford Crater DEM. B. Terrain-corrected Bouguer gravity map (data source Beals, 1960). Model profile shown, crater outline and borehole locations shown C. Residual magnetic map. Crater outline shown.

Figure 3 - 2-D forward gravity model of Holleford Crater. Modelled stratigraphy boreholes (Beals, 1960).

Charity Shoal is a $\sim 1.4 \mathrm{~km}$ diameter suspected impact structure located in easte Lake Ontario (Fig. 1) with a raised bedrock rim and 20-m deep central basin (Fig. 4A). Lake-based magnetic data acquired in 2015, identified a well-defined $\sim 600 \mathrm{nT}$ TMI anomaly low over the basin. A single Airgrav gravity profile collected by Sander Geophysics Ltd (2009) shows $2 \mathrm{mGal}$ low over the structure (Fig 4C). 2-D modeling yields a crater depth $\sim 450 \mathrm{~m}$ (Fig. $5 \mathrm{~A}$ ), consistent with the crater scaling equation for simple impact structures (Pilkington and Grieve, 1992). The TMI anomaly can also be reproduced by a diatreme model (Fig. 5B), but requires a remanence magnetization that opposes the modern field direction. The annular magnetic anomaly may also indicate a zoned low magnetic susceptibility alkalic intrusion (e.g. carbonatite)(Thomas et al., 2016).

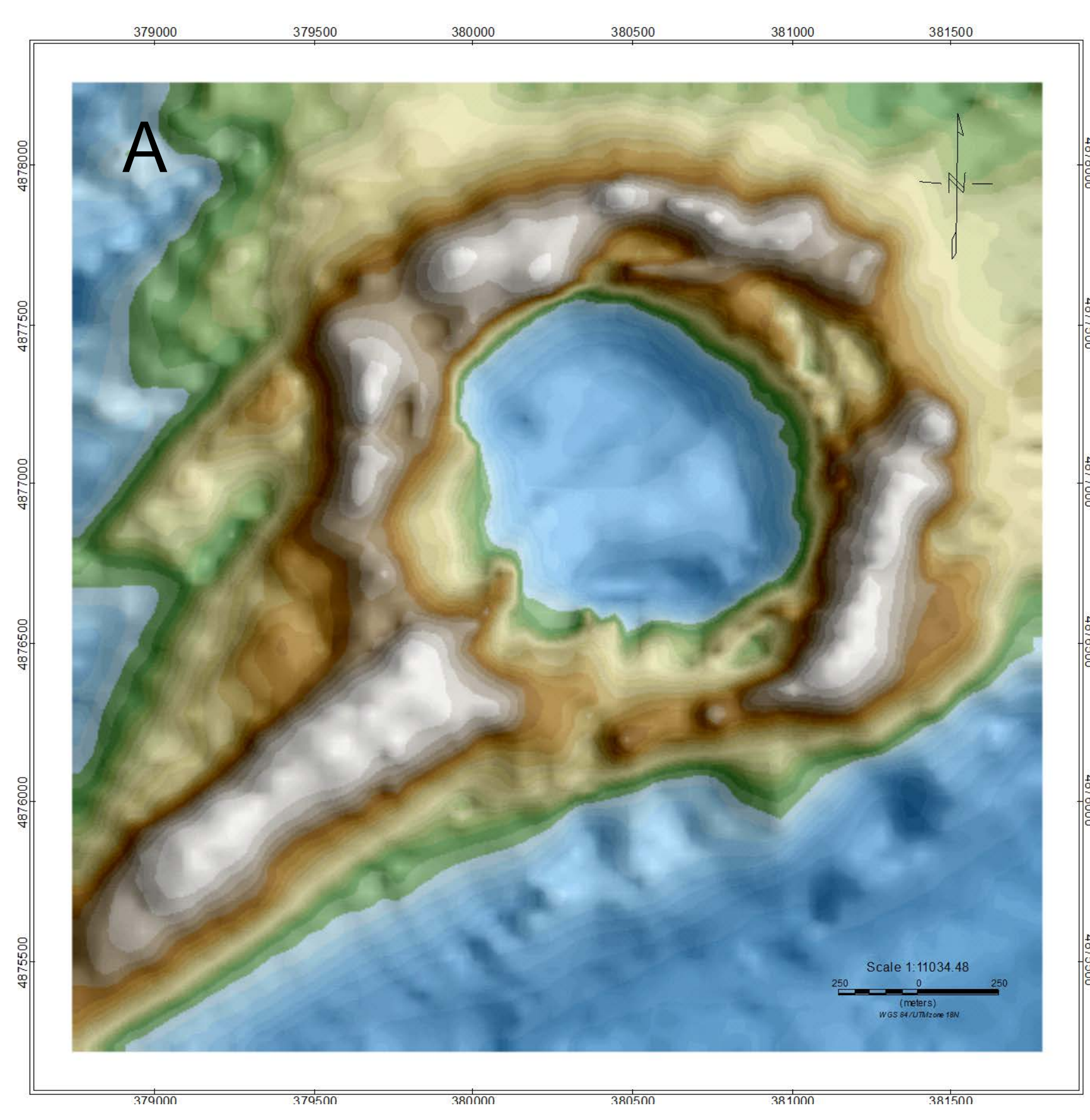

C
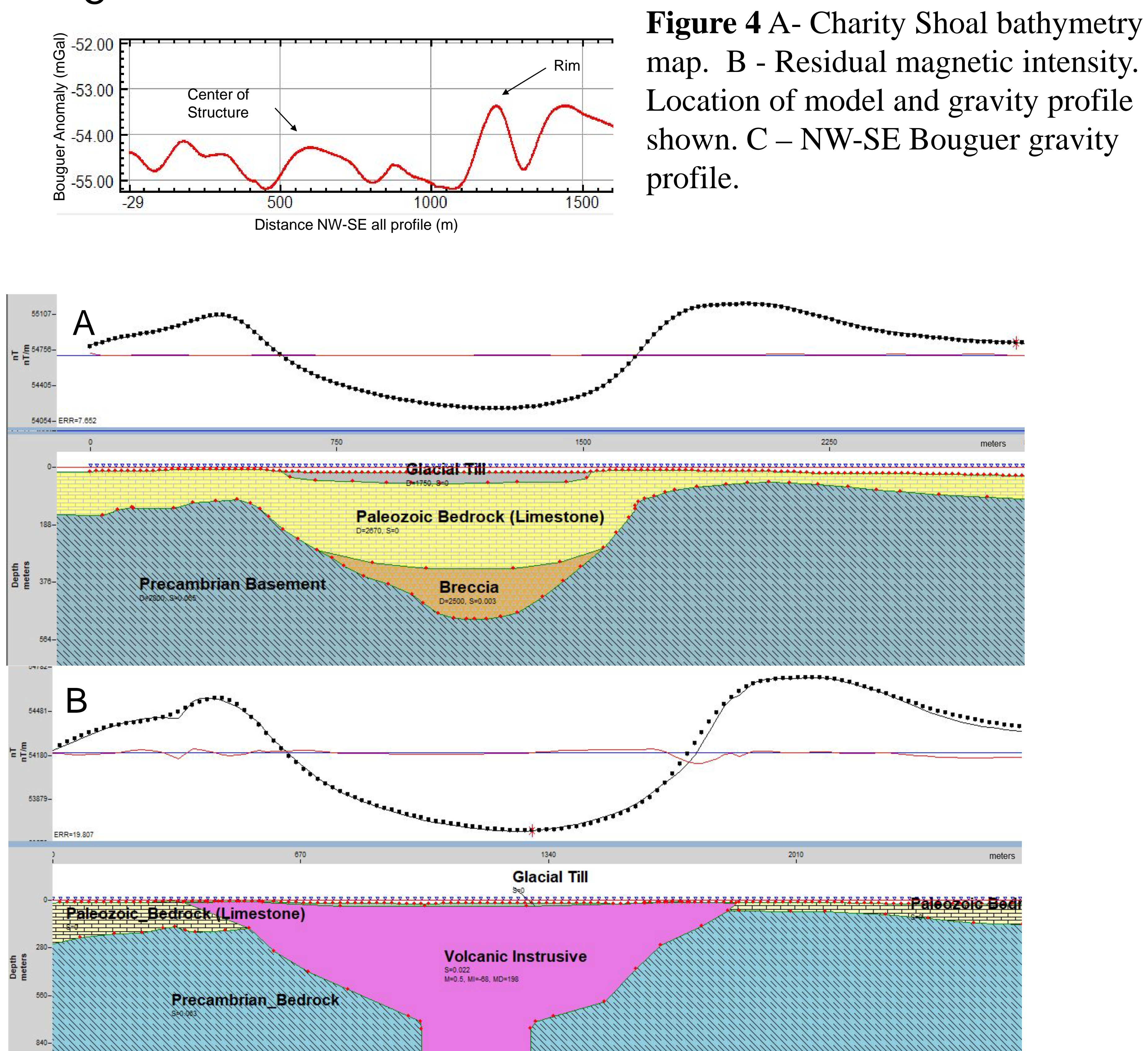

Figure 5 - North-south 2-D forward magnetic models for Charity Shoal. A. Impact crater model. B. Diatreme model (Jurassic age intrusive?) with remanence opposing the main field (Suttak, 2013).
Skeleton Lake is a $~ 3.6 \mathrm{~km}$ suspected impact structure identified in Muskoka Ontario in the 1960's (Waddington and Dence, 1978). Magnetic and gravity surveys revealed $300 \mathrm{nT}$ low over the structure (Clark, 1982) and a 3 mGal Bouguer anomaly. A detailed lake-based magnetic survey was conducted in 2017 to better resolve the magnetic anomaly. New magnetic and bathymetric data acquired in 2017, show that the structure clearly truncates the northwest-trending regional low cenceric fabric. The residual magnetic map shows a $>400 \mathrm{nT}$ magnetic anomaly $\mathrm{m}$. Forward modelling of a simple impact structure (Fig. 7) yields and estimated crater depth of $\sim 500 \mathrm{~m}$ and diameter of $\sim 3.5 \mathrm{~km}$. The model suggests that if Skeleton Lake is an impact structure, it has undergone significant erosion, as the crater scaling equations predict a depth of $\sim 800 \mathrm{~m}$.
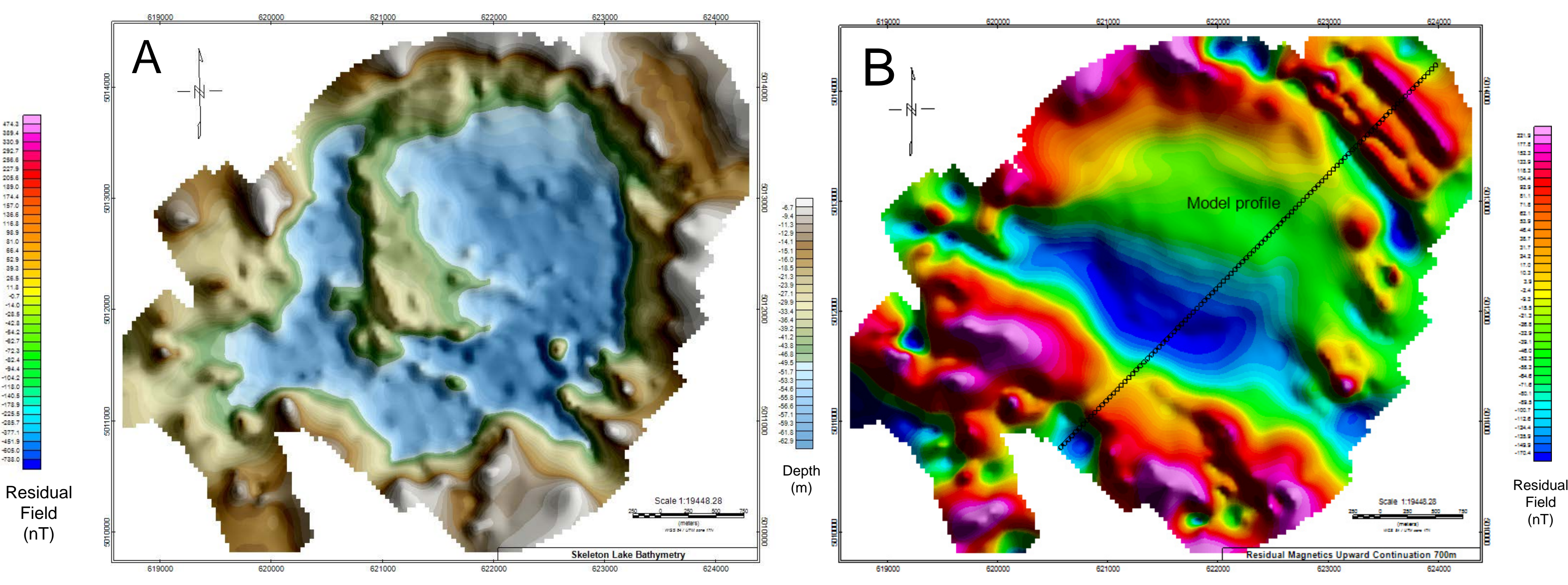

Figure 6 A- Skeleton Lake bathymetry map. B - Residual magnetic intensity map. Line of model profile shown.

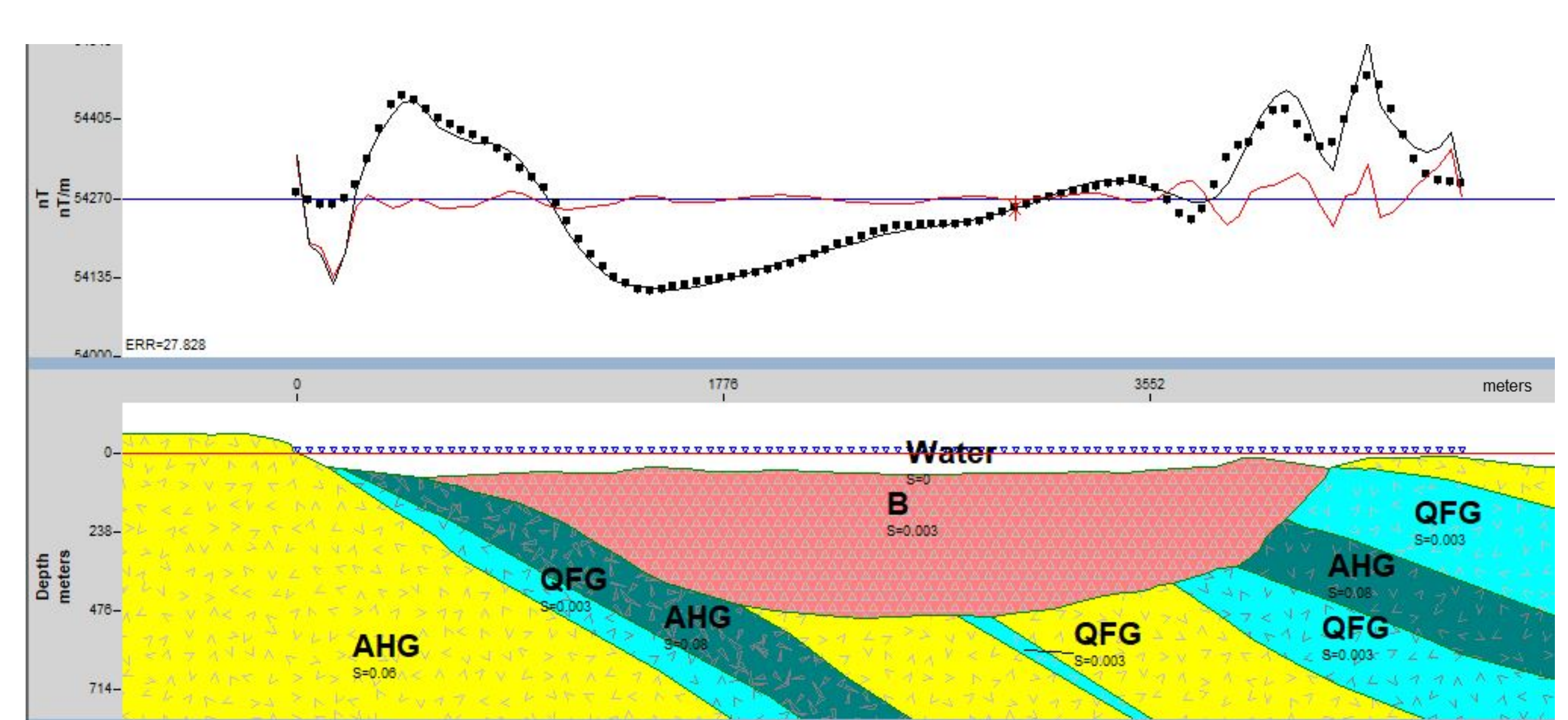

Figure 7 2-D forward magnetic model. QFG= quartzo-feldspathic gneiss. $\mathrm{B}=$ breccia AHG=Amphibolitehornblende gneiss. Magnetic susceptibility values from field measurements.

Geophysical models presented here provide new constraints on the subsurface structure and possible origins of Charity Shoal and Skeleton Lake. However, the magnetic anomaly signatures of two suspected impact structures are significantly different from Holleford crater. This can be attributed to the variable contrast in megnetic susceribilites of infill sedinets and tage

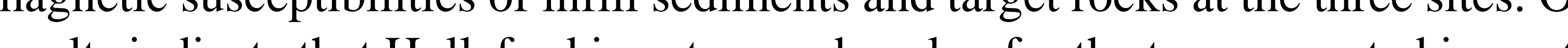
results indicate that structures. Modelling demonstrates that the annular magnetic anomaly of the Charity Shoal structure can be reproduced with a cylindrical source body at shallow depth (e.g. diatreme) with a remanence opposing the main field. This anomaly pattern is also consistent with with magnetic signatures of zoned alkalic intrusions (e.g. carbonatites) described in other areas of Ontario and Quebec (Thomas et. al., 2016).

References

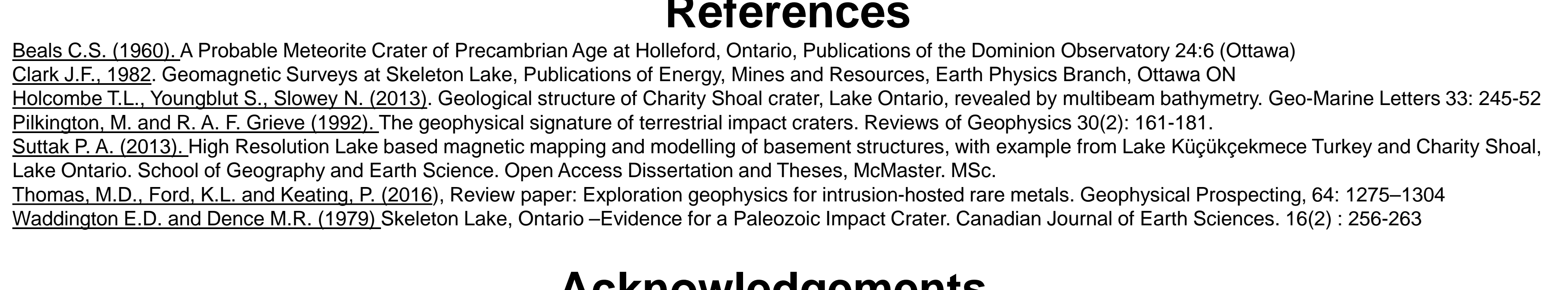

Acknowledgements

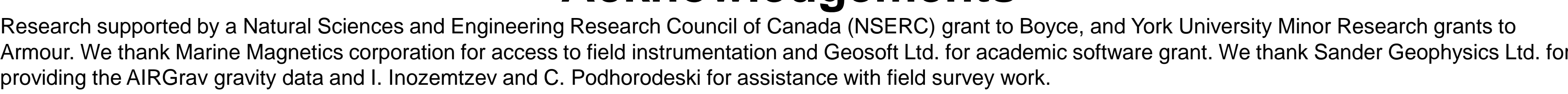

